\title{
Damaged identities: Examining identity regulation and identity work of Gulf project managers
}

\author{
Michael Cowen *, Damian Hodgson \\ Manchester Business School, University of Manchester, Manchester M15 6PB, United Kingdom
}

Received 12 June 2014; received in revised form 13 June 2015; accepted 22 June 2015

\begin{abstract}
Research on the human side of project management is largely overshadowed by its technically focused counter-part. This results in a dangerous neglect of the impacts of a demanding project life and project managers' efforts to construct and sustain a valuable and valued identity at work. In this study of one Middle Eastern IT company, drawing on project management guides, company documents and interview responses from project managers, we examine the regulation of project manager identity using the lens of 'identity work'. We show that intense identity work can be triggered from project life within a challenging environment, and identify various coping strategies employed by the managers interviewed. In some cases, however, we found that these pressures may lead to the project manager experiencing a temporarily "damaged" self-identity. We discuss the practical implications arising from our analysis for project management associations and organizations alike, and opportunities for future research.
\end{abstract}

(C) 2015 Elsevier Ltd. APM and IPMA. All rights reserved.

Keywords: Identity; Human impacts

\section{Introduction}

Globally, the project has increasingly become a preferred form of changing organizations and society (Hobday, 2000). The effective management of such projects is thus a matter of increasing concern, and project management associations (PMA) have devoted substantial efforts in recent years to codify best practices with the aim of improving project success rates. PMAs offer various frameworks, bodies of knowledge and other prescriptive tools to support project managers (PMs) in delivering their roles. However, in practice, executives, steering committees, sponsors, and clients alike pass significant pressure, stress and risk to the PM who is put in charge (Zika-Viktorsson et al., 2006).

This stress and pressure in project life takes many forms, such as limited time, strict budgets, dealing with the multitude of project stakeholder interests, and above all having to deliver

\footnotetext{
* Corresponding author.

E-mail addresses: michael.cowen@postgrad.mbs.ac.uk (M. Cowen), damian.hodgson@manchester.ac.uk (D. Hodgson).
}

the change as defined in the project mandate. Yet, perhaps owing to its long history with engineering, ${ }^{1}$ project management generally follows a rational-linear view of change with what Buchanan (1991) called the content and control agendas, and pays significantly less attention to what Asquin et al. (2010) among others have referred to as the need to bring into focus the human side of the discipline (see also Zika-Viktorsson et al., 2006; Hodgson, 2002; Hodgson and Cicmil, 2006; Lindgren and Packendorff, 2007; Richmond and Skitmore, 2006).

This research is in response to this call. The motive for this study came directly from Author 1's experiences as a practicing PM and the authors increasing concern for PMs who both work under difficult contexts, tight technical and bureaucratic controls. On one hand, managing projects offer a stimulating life but on the other it may come at a high cost including loneliness and long

\footnotetext{
${ }^{1}$ It is well known that project management owes much to its engineering history, however, there is a commonplace that has emerged that sees projects as universally assisting all kinds of project engineering or otherwise (See Paton et al., 2010).
} 
working hours (Lindgren and Packendorff, 2007). This paper directly adds to this reticent conversation using the lens of identity theory, an approach that remains relatively neglected in project based organizations (Andersson, 2009). Identity theory, both in terms of the external regulation of identity and the work which individuals engage in to create and maintain a coherent and valued self-identity, is directly relevant as it sheds light upon the often-overlooked self-disciplinary aspects of project management which contribute to both the pressure and rewards of managing projects. This study explores the effects on PMs self-identity resulting from project life. It draws upon research conducted in the Gulf region, and specifically within the Gulf Cooperation Council $(\mathrm{GCC})^{2}$ context. The authors investigate the ways in which PM identities are regulated, the kind of identity work which is visible, and the effects/outcomes of this on their self-identity i.e., on their sense of self? The argument developed is that idealized PMs as discursively constructed by Project Management Associations and organizations proves to be difficult to realize, particularly perhaps in a non-western setting. The research highlights the potential detrimental effects on the PMs' sense of self, what the authors introduce as temporarily 'damaged' identities.

The research contribution of this paper is as follows: First this paper briefly reviews the vast scholarly interest in identity theory that has had only sporadic penetration into mainstream $\mathrm{PM}$ research to date. This is with the hope of generating more interest into the human side of project life that is not oriented to narrowly instrumental or utilitarian agendas. In order to complete this task the paper provides an introduction to one branch of identity theory - that of post structural/processual research.

This is not to say that this branch of identity is necessarily superior to the many other branches (e.g., psychology, social identity theory), in fact, some (see Brown, 2014) see identity as potentially providing a conceptual bridge for more engaged interdisciplinary work. Second, the paper reviews the existing body of literature dealing with identity within the project management discipline. Third, through an empirical study of managers within the project management group of a GCC-based IT outsourcing company, the authors illustrate the ways in which project manager identity is regulated, focusing on certain organizational and professional PM practices that generate intense identity work on the part of PMs. In certain circumstances this leads to what the authors introduce as temporarily 'damaged' identities.

\section{Introducing identity theory}

There is a broad and influential stream of research across the social sciences which uses identity as a way in which to unpack social processes in a variety of settings. According to Giddens (1991), the maintaining a coherent sense of identity for the individual and maintaining ones' place in society is an important form of security in a complex fast changing world. Identity is regarded as an important lens as it shapes how people see themselves and how they see others, it shapes thinking and

\footnotetext{
${ }^{2}$ Gulf Cooperation Council states include Kuwait, Qatar, UAE, Oman, Saudi Arabia, and Bahrain.
}

behavior, impacting onto personal wellbeing and organization performance (Alvesson et al., 2008). Identity theory is one of the more popular analytical frames in management studies today (Alvesson et al., 2008; Brown, 2014). As an approach, it offers greater understanding into the processes by which individuals, groups and organizations deal with change, ambiguity and complexity. However, one immediate problem with adopting identity in research is the vast plurality of ontological and epistemological approaches.

Brown's (2014) review of identity literature found no less than 1129 articles published in business and management journals. The authors' traversal of identity theory highlighted a number of debates and positions will be placed on a grid as a heuristic for IJPM readers. On one axis, identity research has targeted variable units of analysis from the individual (psychology), through to groups (Tajfel and Turner, 1979), through to organizations (Stuart and Whetten, 1985), and onto society (du Gay, 1996). On the other axis, these objects of analysis identity are conceptualized in differing ways; from being relatively stable, coherent, robust, objective and essential to one extreme to being unstable, insecure, ambiguous and fluid to the other (Butler, 2005). Attempting to cover such a broad terrain within a single research project is not possible, therefore selecting a suitable identity lens was required. From the first axis, choosing a specific object of analysis as solely individual, solely a group or the organization appeared to be particularly unhelpful. The authors wanted to maintain a flexible gaze from the individual, through organization, through to PMAs. On the second axis, neither end of these two extremes of identity as essential, that is to say to be discovered; or identity to be in total flux appealed as a useful starting point. Therefore, in order to be flexible on the nature of identity and the object of analysis a middle way was adopted, that of the processual school.

This processual approach attempts to sit between the poles, identity perhaps being more stable at times but under duress or change identity will become unstable until both context and individual 're-settles'. This reflects a social constructivist perspective that embraces "the possibilities of emergence, plurality, malleability and discontinuity of identity and social embeddedness of identity processes" (Nach and Lejeune, 2010, p.4), and maintains a processual view of becoming, rather than being (Chia, 1995) - asking the question 'who am I, or who are we?' but regards any answers as always only provisional (Sveningsson and Alvesson, 2003).

The authors turned to the influential work of Alvesson and Willmott (2002) who directly tackle this middle way between determinism and agency. This paper will now attempt to explain how their processual model works, through three elements - identity regulation; identity work; and self-identity.

Identity regulation is typically seen as a range of external forces, deliberately manipulated with the aim of "regulating employees 'insides' - their self-image, their feelings and identifications....a pervasive and increasingly intentional modality of organizational control" (Alvesson and Willmott, 2002 p626). Many writers on identity regulation suggest that this is an increasingly important focus for organizational attempts to influence the behavior of employees. Alvesson and Willmott's 
intention with identity regulation is not to target bureaucratic organizational control but rather redirect attention toward self-administered technologies such as appeals to emotion, passion, and conscience. Although Alvesson and Willmott were not the first to argue for research in this field, (see Mintzberg, 1983; Knights and Willmott, 1989), their article is regarded as "one of the most comprehensive discussions on how identity is regulated in organisations" (Wieland, 2010, p506). Identity regulation technologies aim to achieve control through prescribing acceptable organizational practices that address the individual's skills, group situatedness, context, rules, mission etc. They group these as defining explicitly or implicitly the person in comparison to others, regulating action via socialization. This process is informed by standardization, procedures, context, and rules, controlling social relations, and manipulation of the setting in which the individual, group, and organization operates. Their examples of identity regulation include induction, training, and in-house communication, promotion, and HR policy so that individual employees embrace the concept of 'we' and 'us' instead of 'the company' or 'them'.

By contrast, identity work refers to the ongoing conscious and subconscious actions of individuals "engaged in forming, repairing, maintaining, strengthening or revising the constructions that are productive of a precarious sense of coherence and distinctiveness" (Alvesson and Willmott, 2002 p631) - the efforts to build and maintain self-identity in the face of a range of external pressures. Identity work can be seen as "anything people do, individually or collectively, to give meaning to themselves or others." (Schwalbe, 1996, p115). Identity work can be used in many contexts e.g., individuals, groups and organizations in transition or transformation (Alvesson et al., 2008), however it is used in the micro/individual sense here. Alvesson and Willmott come to the conclusion that the most potent of identity regulation is in fact hidden within people's identity work i.e., where people believe they have free will and are making their own choices. It can be seen as a struggle against various forms of discourse which prescribe an ideal-self which individuals then may attempt to 'live up to' as they internalize externally-prescribed 'ideals'. Some identity work literature adopts a positive trajectory (see Thornborrow and Brown, 2009) where an employee's identity work results in a stronger sense of self, or heroic depictions of agency over structure - there are, however exceptions (see Beech, 2008), and it is this latter 'negative' depiction that emerged from this study.

Sveningsson and Alvesson (2003) have shown how identity work can be used as a stabilizing process of self-identity drawing deeply on historic personal narratives. Self-identity emphasizes the reflexive nature of identity formation, hence Giddens' definition of self-identity as "The self as reflexively understood by the individual in terms of his or her biography." (Giddens, 1991:53). The term self-identity refers to that deep sense of one's self, visible through one's self narratives, acknowledging that self-identity is a dialectic process between past and future, and also between inside understandings and outside presentations (Beech, 2008). What these authors therefore focus on is the struggle between determinism and agency, in particular, how these can create gaps between what management expects from its workers and what is actually performed.

Fig. 1 captures how these three elements of the processual model interact. This model demonstrates how actors might attempt to control PM behavior through shaping identity (identity regulation), how the PM might actively work on their self-identity through identity work.

\section{Identity in project management research}

Despite the ubiquity of identity research across management and organizational research and the wider social sciences, it appears that this has had limited impact to date upon the project management field. There are however some notable exceptions, which are discussed in more detail below. Frequently this work addresses the notion of the 'ideal self', and Wieland (2010) studied PMs in a Swedish firm, finding that PMs enacted an ideal self as 'a deliverer', "[one] who delivered, who produced what he or she was expected to produce according to timeline" (p515). Claimed in the study was a conflicting yet further demanding ideal self as 'one who practices well-being', in other words, a PM who was also in complete control of his project, who delivers and at the same time maintains a healthy worklife balance. One driver of this ideal self was through the performance review process that was used by the organization to shape peoples sense of who they were, and served as not only material rewards but symbolic ones. Through the performance review process, PMs were encouraged to put specific work/life balance goals e.g., not working more than $40 \mathrm{~h}$. The company's surveillance system would highlight in red if PMs reported working more than $44 \mathrm{~h}$ for their line manager to address. These two conflicting identities in the study seemed difficult for PMs to negotiate, hence Wieland found that PMs would hide their 'true' hours in the office or on the project in order to meet expectations of themselves as 'one who delivers'.

In a similar vein, Paton et al. (2010) found that PMs experienced a deep discomfort in the process of trying to enact the 'idealized identity' of the PM. They proposed that this discomfort and tension to be created by factors such as status, perceived organizational value, power, influence and role ambiguity. Much of this tension resides in the particular conception of professionalism dominant in the field of project management (Hodgson and Paton, forthcoming). Importantly, the research found that PMs maintained a sense of disempowerment, contrary to the rhetoric of PMAs where the PM is the Chief Executive Officer of the project.

A related but distinct stream of work in this area focuses instead upon the personal and human consequences of the construction of a particular project management identity. Andersson (2009) examines the way in which PMs use the project itself as a resource in the construction of their identity. He highlighted that the project becomes one of the primary instruments to translate organizational values across team members and stakeholders into products. Andersson suggests that identity of the PM and of the project are 'co-constructed'. This puts PMs in a precarious position of having their identities 


\section{Alvesson \& Willmott Model}

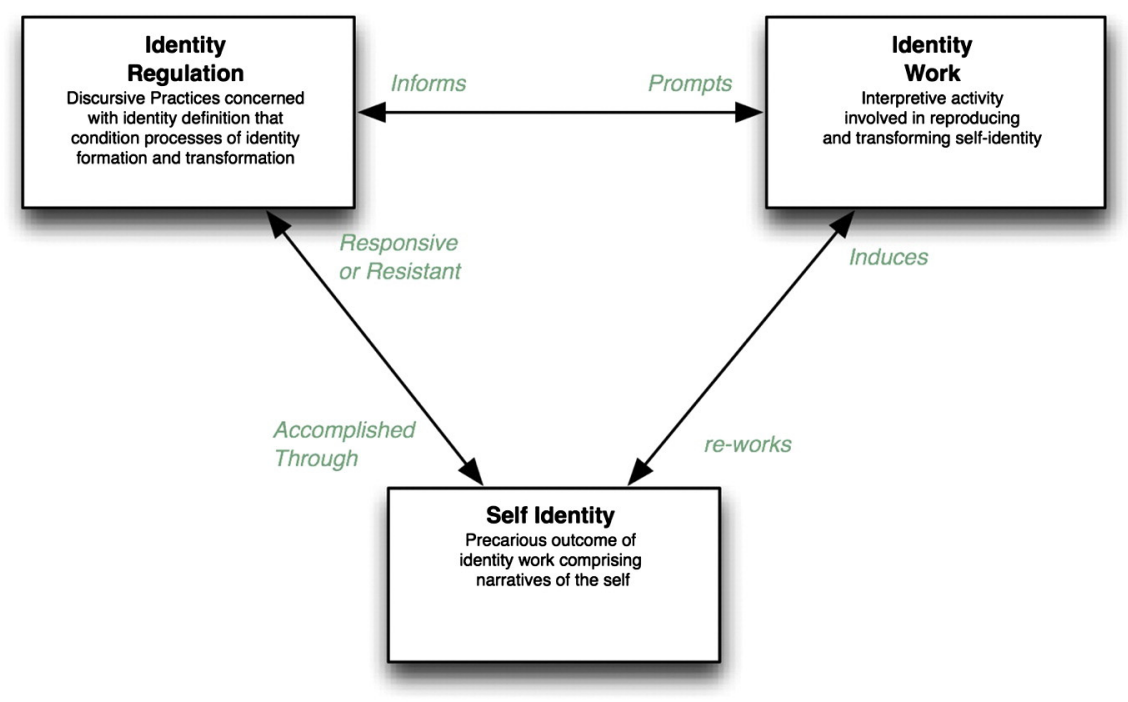

Fig. 1. (Adapted from Alvesson and Willmott, 2002: 627).

closely tied to the fate of their projects, with powerful effects which are often unrecognized or taken to be 'voluntary'. This has the potential for organizations to use the identity of PM to mean long hours, total ownership, sacrifice, and going above and beyond the call of duty for the PM. Lindgren and Packendorff (2007) further develop the theme of work intensification and wider consequences suggesting the PM risks "implicit stress, loneliness, disrupted family lives, superficial work place relations etc.” (p354). In their study they saw four discourses in operation; the 'state of emergency' discourse with economic and/or political threats that burden PMs; the 'loyalty and professionalism' discourse, that somehow project members owe the project and organization something; the 'organized chaos' discourse where project management melds the rational and linear with the urgent, emergent and emergency; and the 'war stories' discourse where PMs talk about the difficult life enacting the role. These discourses were found to embed themselves in a co-construction of project and project professional identity.

Collectively, this work identifies certain consistencies in the way identities impact on our understanding of projects and project management. Wieland (2010) shows how not only organizations regulate the identities of PMs but how a broader cultural shapes worker identity. That identity work is less focused on a concern for uniqueness or coherence, but rather is fueled by the necessity of being accepted in a given social setting. Paton et al. (2010) discovered a sense of identity politics or strategies used to cope with these tensions with attempts of their identity regulation such as having a strong belief in the science of project management, re-writing their respective histories, and reverting to/ using alternative job titles. Lindgren and Packendorff (2007) show that while projects appear stimulating for employees there are potentially negative impacts on them and their lives. What these authors achieve adopting an identity lens is the foregrounding of a concern for the human consequences of project work that are frequently silenced by the technical and positive representations of the project management profession.

\subsection{Methodology}

To understand identity work and identity regulation through PM accounts of their practices a qualitative case study at a single site methodology was chosen. A single site was chosen in order to work with "thick" accounts (Geertz, 1973). It is acknowledged that this approach immediately makes generalization to wider populations problematic, however, this is not the objective. The authors see generalizing to the identity literature as sufficient.

The case study organization is an IT outsourcing company "ITOC" based in a GCC country. The company was founded in 2005 in a joint venture between a US IT Outsourcing company and a local investment company, growing from 25 employees to more than 600 within a couple of years. The mission of the organization is to provide quality IT and business process services that add value to their clients' businesses using...'... highly committed and motivated teams using innovative thinking and best practices." (Source: ITOC website). Since its inception, ITOC supported a combined Programme and Project Management Group called the PPMG that united all PMs from around the organization into one cohesive unit that at that time (2005-2008) was well supported. The creator's vision $^{3}$ was to develop a strong sense of identity for PMs; however, after the group creator and leader left the company in 2009, support for the PPMG unit declined until it was eventually

\footnotetext{
${ }^{3}$ This was from an interview with the creator of the department who explicitly adopted the term 'identity' in his account.
} 
broken up into 3 subordinate functions within other departments under infrastructure operations, finance, and software.

Author 1 worked for ITOC for a period of four years in the role of PM nevertheless, three of those four years were largely outside the organization being placed into client sites for extended periods. The researcher therefore had access to what Erving Goffman describes as the 'back-stage' areas of the organization, yet still maintained some intellectual distance from it. The author ceased employment at ITOC after the data collection phase of the project had completed. This departure was entirely unrelated to the research project.

The empirical fieldwork was conducted between January and July 2011. First, relevant documentary evidence from PMAs were collected including: PMI's Guide to Project Management Body of Knowledge $\mathrm{PMBOK}^{(\mathrm{R})}$; PMI's Code of Conduct and Ethics; and OGC's Prince2 Body of Knowledge. Reviewing this type of material provided important information in terms of external discourses from PMAs like PMI and OGC. Second, numerous ITOC documentary evidences were collected. Reviewing this type of material provided contextual information that helped position interview data, compile accurate historical information, company structure and organizational discourse surrounding project management.

The interviews were conducted in May-July 2011 using semi-structured interview techniques. Multiple perspectives within ITOC were sought from PMs, Project Management Office, and leadership across both software and infrastructure projects in order to better establish dominant discourses. In total 16 PMs (64\% of the projects group) were interviewed who were recruited by email, plus 3 PMs who had recently left ITOC, and one who had recently transferred from the project management group to an operations role. Interviewees covered a broad range of experience and categories such as religion, nationality, experience, age, and gender (see Table 1). This is only to stress there was a wide range of nationalities, religions, years of experience etc. The authors did not attempt to make any comparisons across the sample. The identity of all participants and any referenced organizations has been carefully disguised.

Interview questions were prototyped by the researcher with colleagues before the first interview, revised and were refined at the half-way point of the interviews. As an indicative example: Do you find yourself in situations where the 'PM' is required to behave or do things in a certain way? From these influences: peers, projects, PMOs, PBOs, PMAs etc. to what extent do they shape your practice and shape you? Most of the PMs were known to author 1 for up to four years. The interviews were semi to unstructured to allow a flowing conversation about their careers and practices, establishing broad themes and questions and yet not being constrained by them. Many of the participants had unique stories to tell e.g., being fired from ITOC, being female, being a National, and recently leaving the project management profession. Interviews ranged from 75 to $180 \mathrm{~min}$. Six interviews were undertaken at the company location, and the remaining 15 were held in coffee shops. The interviewer requested that the interviewee select the time and the place convenient for them to ensure a neutral comfortable environment enabling the participant to talk freely about their experiences (Easterby-Smith and
Table 1

Process model of identity regulation and identity work.

\begin{tabular}{ll}
\hline Experience & Demographics \\
\hline $\begin{array}{l}13 \text { had active professional certifications, } \\
1 \text { was suspended and 1 expired. }\end{array}$ & $\begin{array}{l}\text { The twenty interviewees were } \\
\text { from } 13 \text { different countries. } \\
\text { interviewees did not have their }\end{array}$ \\
$\begin{array}{l}\text { Claimed project management experience } \\
\text { was an average of 11 years, minimum 5, } \\
\text { maximum 23. }\end{array}$ & 13 were Arab \\
$\begin{array}{l}\text { The average number of years at ITOC was } \\
\begin{array}{l}3.38 \text { years. Minimum 2 months and } \\
\text { maximum 6 years. }\end{array}\end{array}$ & $\begin{array}{l}16 \text { were Muslim } \\
\text { Average age was } 39 \text { years old } \\
\text { Three were female }\end{array}$ \\
\hline
\end{tabular}

Thorpe, 1991). In-depth interviewing was adopted as it offered a superior combination of structure and flexibility in order for the researchers to explore identity processes and outcomes (Patton, 2002). A seven stage protocol was utilized including: arrival; introducing the research and obtaining informed consent; getting PM background; exploring the key themes guided by the researcher; ending the interview; and finally thanking the interviewee and reaffirming confidentiality.

All interviews were recorded, transcribed and loaded into NVivo for analysis. The interview transcripts and documents were systematically reviewed and coded into 'grounded' categories according to the identity themes emerging from the data (Gillham, 2005). At the end of this stage over 1,100 codes were created representing identities, influences, and ideas from this interpretation. These 1,100 codes were then revisited and organized into parent categories. These parent categories included: "external influences" (e.g., PMA discourses, the client), "internal influences" (e.g., code of conduct company values); "Coping Strategies" (e.g., using artifacts as defense, managing the self); and "Consequences" (e.g., for the project manager or for the organization). "Noise" (i.e., codes interesting but not related to research emerging themes) in the data was subsequently removed at this point. To improve the validity of these grounded codes (Gillham, 2005), another researcher and PM was invited to analyze a sample of 6 interviews. This researcher has no background in identity literature and no knowledge of ITOC perhaps getting closer to being able to work from a 'tabula rasa'. Subsequently, both researchers met to discuss each other's codes. The grounded codes were then reviewed one by one for their applicability and usability in the processual identity model. Finally the researchers took the codes through an iterative cycle of theorizing. Analysis spanned a period of three months to complete.

When adopting a critical perspective and qualitative research reflexivity of the researcher is paramount. The authors' values, experiences, knowledge, character, personality, culture, language, politics, and ethics play into any construction of this papers argument, and even well before this - in the very subject and question of the research itself. As qualitative researchers, we would argue that total objectivity is never possible, or even desirable; all interpretation is influenced by our background, experiences and formation and the challenge is to be reflexively aware of thisThis is clearly the case in this study as Author 1 worked at ITOC for a period of four years. This experience at 
ITOC in comparison to some of these interviewed in the study was a positive one, albeit at times strange as a Westerner working in the Gulf, often for demanding government clients. Using an outsider to discuss coding and themes served to articulate and clarify the impact of previous experience on the analysis - as project manager, employee and insider-outsider in both the firm and the state.

\section{Key findings}

\subsection{Identity in action}

Identity regulatory attempts are clearly visible in the case study organization.

First, professionalization shaped the practices and identities of PMs. An example of this was evident in references to the certification received through the Project Management Institute (PMI). The certification was viewed as a form of job security through identity differentiation. PMP certification for Abdul offered a feeling of greater security and he saw the certification as a way of curing his weakness in financial management. He differentiated the deeper self-identity and professional identity by adding that PMP was not to transform his character, just to 'enrich the existing me'.

"When I mentioned to you that I have one of the weak areas for example how can I financially manage the project? When I got the PMP I got this area remedied....If I'm adding knowledge at this particular period in my life, I'm adding it for my benefit. It is not to transform my character. It's not like I'm going to training to compensate this... no. I'm going JUST to enrich the EXISTING me. The certifications will provide a greater feeling of security and recognition." (Abdul)

Second, all PMs interviewed claimed that ITOC was an immature organization that suffered from low trust and low empowerment from its workforce. This in turn shaped the manner in which they present themselves when delivering projects internally and for clients. Since that time, the PMs claimed that organization support has been constantly reducing, that no one was fighting for them, and that their resulting position in the organization - at the same level as the technical resources - was a loss of status, making it very difficult to practice with authority. Since the time of the PPMG split in 2009, they argued that it had been increasingly difficult, owing in particular to the lack of support for project management process and the limited legitimacy of the role. This in turn made it unpleasant to maintain a PM identity among other, more highly valued organizational identities e.g., account manager, service delivery manager etc. Some PMs went so far as to describe the PM identity as a 'scapegoat identity' ready to be blamed.

"Management have full control of the PMs because of the lack of support. By destroying the PPMG they made the group weaker, and better control the PMs... Always in this structure the PMs at the end of the project will always be blamed. They are not solution architects if something is missing. 100\% PMs get blamed always." (Yazid)

The Project Management Office (PMO) Head took a great deal of pleasure controlling very carefully what PMs could and couldn't do,- - to such an extent that he referred to PMs with antagonism, somewhat like prisoners on probation, where he was the jail guard, and 'if you don't like his way then into the hole'.

"You can take a horse to water but you can't make it drink, so instead, you kick the horses ass into the water, and make it drown actually. You drink you are enlightened. There is heaven and hell, man, I'll show you heaven, but if you don't want heaven I'll push you into hell...All projects have issues-PMI says so. If you don't do this analysis yourself you have shot yourself in the leg. I did not shoot you-you did. I only said there is a big gaping hole there. You already shot yourself in the head-I'm not Gestapo. I'm a bringer of light. [laughs]." (PMO, Head)

Many PMs interviewed reinforced the PMO Head's missionary rhetoric of PMO methods as being 'the law, the bible, the one truth', with biblical consequences if it was not followed. Some however, would be asking themselves questions of whether the PMO reports they produced reflected actual reality or were they doing it only to "window dress" the project shop front. The "PMO is law' position was explicitly stated or implicit across most PMs. PMs claimed that it was not safe working in ITOC with volatile clients in an immature organization that was unsupportive of the discipline of project management or PMs themselves. The escalations that the PMs were most concerned about is when the client calls ITOC's Managing Director, CEO or CFO directly; or the reputation damage from showing red status on the PMO's monthly dashboard, or internal PMO non-conformance emails to their line managers.

So how did these examples represent identity regulation? In the case of PMP certification, a technical language, discursive practices, and idealized identity of the PM was imposed on the individual — setting out what a PM 'is', how they should behave internally at ITOC and with clients. If a PM does whatever it takes to deliver on time and to budget then, these values became the values and practices of the PM, sometimes without much critical thought. Understood as 'regulation technologies' in the model of Alvesson and Willmott, such practices define the individual directly or indirectly, through the construction of knowledge and skills, and through their hierarchical location in the organization. When the organization broke up the PPMG department, when the organization failed to support PMs, or the PMO antagonized the PMs - this results in more intense identity work.

In order to survive the ITOC working environment the PMs provided evidence of a great variety of identity work strategies utilised. These included managing the self i.e.,. maintaining resilience, maintaining self-confidence, re-framing negative thoughts into positive learning experiences, avoiding work overload, deflecting non PM responsibilities to their respective 
owners, and 'loving' the challenge of project management; and relational strategies e.g., being positive, playing the political game, avoiding face to face time, and avoiding conflict. Two surprising strategies will be expanded upon now-project management methodology as defense, and window dressing. The systematic and document-driven 'science' of project management offered PMs a potential coping mechanism through the usage of these artifacts as defense, as agreements. For example, scope statements, base-lined schedules, budgets, even risks stated on a risk register.

"Everything is with agreements. I had an issue with one person [who refused to work for a female PM]...I sent it as a risk...to everyone. This is a risk and I cannot accept it. Either they have to resolve it or if they believe that I'm wrong, then they have to replace me."(Malikah)

This technique assisted in the protection of PM identity by putting documents, artifacts, agreements, or boundary objects in between him/herself and the organization or client. 'It is not me-it is the risk'. In the above case Malikah says to management, "mitigate the risk by removing this resource or select another PM". In this way, as projects invariably can go wrong in these immature project environments the PM hides behind the science that protects her reputation, and ultimately her sense of self.

PMs frequently talked about the need to defend themselves against attacks on them, their reputations and identity from the PMO surveillance and auditing processes - the most popular tactic was "window dressing" project documentation. This strategy involved an acknowledgment that the project reality and the reality reported to the ITOC PMO was different, not to hide reality as such, but rather to 'get a monkey off their backs' and to get on with the work of delivering;

"To meet the audit requirements...[one]..can have put a few issues in an issue log, put some risks in but it adds no value to you. It is window dressing, it is very easy...window dressing is done all the time over here." (Nahbi)

"You just make sure you update the workbook... nobody has the experience to say this is fabricated or this is the reality! You do window dressing!" (Matthew)

"When you look at the status report contents it actually has nothing to do with what is happening in the project. It's not a real representation of the project status." (Tamim)

The strategies identified represent different ways that the individual PMs performed identity work. These related less to the 'forming' of identities (as much of this is implicit in their PMP certification process), but more in terms of protecting identity through repairing, maintaining, strengthening and revising conceptions of the self. For example: in the difficult context of ITOC, managing the self, and maintaining positive relations with others, and loving the challenge are ways of maintaining their positive sense of selves and efficacy. Using the documents as agreements, and window dressing a positive image of the project are proactive forms of protecting their sense of selves, and positive PM identity. But, given these empirical examples of identities under construction and negotiation there was another unexpected finding - that of PMs who endured collateral damage to their careers and self-identity.

\subsection{Damaged identity}

There were extensive examples of the negative consequences of project life from dealing with stress and pressure; not having control over one's time; significant personal sacrifice; low motivation and engagement; and the PM appropriating time i.e., working much less than 100\%. The consequences here can be understood as part of what we have described here as a "temporarily" damaged self-identity. By damaged, this is to mean in the sense of inflicting harm on someone so as to impair his perception of his own value or usefulness in the PM function, resulting in seeing oneself as lacking, as less than before one took on the PM role. In order to examine this, the paper will delve into one particular PM's story, hereafter referred to as Haytham.

Haytham was given a very difficult project to manage with a client that a number of his fellow PMs referred to as 'crazy'. He aggrandized his narratives generally, he spoke of himself being much stronger, and more professional because of this experience. Nevertheless the interview had an air of resignation to it, a defeated tone as he had not only recently failed to deliver a project, he 'chose' to leave the profession altogether.

"I have gained unbelievably a lot of experience working different types of projects, different types of organisations... and that really strengthened my individual confidence.... what client you give to me, no matter how complicated a project-I will never say - I will look at it, and think about if I can do it, and if I believe I can do it, I have got the confidence to manage regardless of the size of the project... I feel a much more stronger person, much more professional, um, much more experienced. I've managed projects with 40-46 people."

After 10 months on this project, Haytham eventually reached a breaking point and decided he had to leave the project, or leave the company altogether. For him the price of success had become too high. He blamed himself for taking the responsibility of being the PM too personally, and he felt guilty about not spending time with his family. He claimed he took 'ownership' of the project to an extreme level although this dedication to delivery was not uncommon from the PMs interviewed. He added...

“...I was giving everything I could. I literally sacrificed my social life, my family life, everything I could do for this project. The only thing I would blame myself is 'Haytham should have acted like everyone else rather than working off his butt...', I realised, at the end, I realised that no one is taking the commitment seriously. No one, has the intention of helping me deliver and no one gives a shit about the whole project. I realized all of this at 10 months..." 
After his wife threatened divorce, he described the need to make some drastic changes. He negotiated to leave the project, and to leave project management all together to move into an operations role in service delivery in the ITOC Data Centre. He explained this was a role where he feels much safer, and where he can control his time better, and re-address the issues of not spending enough time at home. He admitted project burn out, and was in transition to operations.

"I felt like [long pause] I almost got divorced. My wife asked for a divorce a second time while I was on this project, because I would leave [ITOC] at 9 pm go to [home] 1010:15 pm, get changed, and see my kids before they go to bed, change and go to a coffee shop until 2 am. Ask anyone. My emails were coming through from every single moment-anytime... I worked 26 weekends.... I took complete ownership of doing delivery... I was able to manage all of this. But the only thing I was not able to manage as much as I wanted, I felt guilty about, is my social life....But when I realized that no one could give a dam about this... I could not continue with that...[My wife commented] 'You have 24 hours in a day, you sleep 4 hours-where is the other 20 hours?' Honestly I had to wake up! I had to wake up!."

He had been in the role only 2 months at the time of the interview, and showed signs of intense identity work underway including new professional certifications. Haytham rationalizes his self-narrative since the move to operations and he sees this new chapter as strengthening and growing his identity, and power in the language resources he has to use in various work situations as PM and operations manager. During the interview, Haytham appeared to put on a brave face, however he could not totally hide the resigned tone of his voice and the defeat from a project that failed, ${ }^{4}$ a marriage that almost failed, and his moving to safer shores.

"I'm now a service delivery manager...I'm changing my identity. I'm planning to change my identity. And this is the plan I have....Now part of my plan, the next move is to turn purely into an operations manager role. Which is why I have done my masters in strategic information systems, and...in parallel I'm planning to do Data Center certifications, and ITIL. So, this will change my identity from a PM person to an Operations person with that mentality. So it will be one of, I will be...operations and pure strategic planning with project management skills."

\section{Discussion}

In this section the authors maintain the goal of debating the human effects of project management by using this case study to extend Wieland's (2010), Paton et al. (2010), and Lindgren and

\footnotetext{
${ }^{4}$ This was confirmed after a detailed discussion of this interview transcript with the second coder who viewed a sample of interview transcripts.
}

Packendorff's (2007) work that not coping with the demanding work leads to the potentially damaging effects on PM identity.

Wieland's (2010) shows how identity work is not only descriptive but also evaluative i.e., it contains a moral value, the good or the ideal self - the self I want to be (Giddens, 1991). The implication here is the PM identity is constructed with a sense of what is a good PM. This good is imbricated with the social acceptability of the project, the group, the organization, and/or the profession, and the society as a whole. Importantly, Wieland identified the tension between the internal PM professional discourse, 'PM as deliverer' that came into conflict with external ideal of Swedish discourse PM 'as one who practices wellbeing'. Supported here by Jian (2011), organizational discourses are themselves colonized by broader muscular business discourses like that of project management, and powerful actors such as the Project Management Institute. Organizations adopting project management practices need to be cognisant of how these muscular discourses affect PMs, and their identities.

The ITOC case study highlights further tensions not only between these organizational and professional discourses that attempt to shape the identities of PMs, but that of the expected versus the possible. First, this occurs when the PMA 'PM Body of Knowledge as a flexible framework' does not match the organization's ideal of the 'PMO methodology that must be rigidly followed like the letter of the law'. Is the PM a creative artistic agent or a myopic process robotic? PMAs can be accused of exaggerating the capabilities of project management as part of their own marketing to employers, clients and prospective members, resulting in certain expectations thereafter affecting anyone with that designation. On one hand restrictions on PM freedom can negatively affect project performance by reducing creativity and adaptability to project life (Van Donk and Molloy, 2008). On the other hand, the lack of standardization and normalization can reduce predictability and performance. This professional and organizational tension sometimes referred to as the "professional-bureaucratic conflict" has not been well supported by empirical research (Gunz and Gunz, 2007:853). They point out that through adaption, professionals navigate easily their professional identity with their organizational identity. In this study however, PMs showed a preference for their professional identity and distanced themselves from organizational identity.

Second, this occurs when the PMA perspective of the legitimate PM with a solid science underneath it does not match the lived experience as in ITOC, as project stakeholders do not value, support, or give credence to project management as a science. It would seem that PMAs and organizations alike may maintain an identity regulating monopoly over the PMs, however, there were a wide range of strategies employed, and these match closely to Collinson's (2003) notion of the conformist, resistant, and dramaturgical selves. Conformist in terms of managing the self; rationalizing; aggrandizing narratives; dramaturgical such as keeping good relations in spite of problems; using the science of project management and artifacts as agreements; and resisting identity attack such as time appropriation and avoiding PMO audits. The strategies were identified by 
Paton et al. (2010) — the strong belief in the science of project management, re-writing career histories, modifying job titles - can all be seen to some degree at ITOC.

Third, this occurs when the organization espoused support for the PM (e.g., in meetings in front of clients) does not match the experience by the unsupported PM (e.g., treated as a scapegoat to be blamed in case of failure and not trustworthy to deliver) One telling stage for intense identity work was at the ITOC PMO audit. PMs claimed that an antagonistic management was insensitive to their difficult working conditions and PMO did not hesitate to name and shame them in audit meetings or project dashboards. The head of project management told of a major altercation between an executive manager and a PM, claiming the PM was not a PM at all. Another stage was through "window dressed" project status reporting, an important method to focus on one's project and avoid attack on one's identity. The authors posit here that these complex and multi-dimensional forces can prompt significant and frequent identity work in the PM. The larger the gap, the more intense the identity work. To demonstrate this aspect, here is an example from one of the PM. In this part of the interview, Yazid was describing previous projects that were incomparable in size and responsibility, showing the PM identity as the top dog, with the power to create, to change scope, and have an impact on the organizations and project team members lives.

"When you are a PM you are God, that is my definition. You have everything, you create, you delete you do whatever you want. You are a God in this project. This is my definition." (Yazid)

Now compare this comment to another made by him in the interview. In this part of the interview, Yazid was highlighting with much frustration and disappointment to be so undervalued within ITOC. When the legitimate 'PM as CEO, as leader, as autonomous decision maker' does not match the reality as practiced with the 'PM as coordinator, as follower, and as documenter' intense identity work follows.

"A PM from them [management] is a project coordinator. A senior, i.e. me within ITOC is just a coordinator...”

Extending here Wieland's (2010) notion of the ideal PM identity depending on the size of the gaps and strength of the tensions creates space for PM identity work. This study was set in an IT setting in a non-western region. The lack of support, demanding clients, an antagonizing PMO, and serious gaps in expected verse practice make it difficult for a PM to maintain a coherent identity. High expectations from demanding clients caused some PMs to question their self-worth as project managers. The perceived low value, low skill, and toxic antagonism from the organization set up the PM for identity attack, particularly on the stage of the PMO audit with participation of senior managers. As in the Lindgren and Packendorff (2007) study factors such as stress, pressure, and personal sacrifice were seen here. PMs are being dominated by the project, by the client, and by the organization all under the pretense of "being a professional", resulting in consequences of time not being their own; personal (family) sacrifices; and stress all implicitly expected of them.

Self-identity effects varied a great deal on a case-by-case basis in this study depending on the efficacy of identity work strategies. Andersson (2009) posited three alternative interpretations of their research on PM identities: PMs as helpless victims; PMs as responsible agents, or somewhere in between. This case study suggests that identity constructions are better viewed as somewhere in between. The PM is working around and in between the tensions and the spaces created between the regulated identities and their identities as practiced. While Lindgren and Packendorff (2007) found the PMs that suffered from stress, pressure, and personal sacrifice, and that PMs accepted the plight that came with the role. As Legault and Chasserio (2011) point out, a happy client and project success is associated with promotion for PMs, therefore they rationalize that these sorts of costs are acceptable, and often temporary. Nevertheless, even though the project is temporary, there is another project and new client awaiting the PM and the cycle will repeat itself again.

Unlike Lindgren and Packendorff (2007) who posit a visible 'loyalty and professional' discourse, this appears absurd at ITOC given the anti-ITOC and anti-PMO discourses. The antagonism toward the ITOC PMO toward PMs, and the consequences such as a lack of autonomy, additional stress, and a sense of disempowerment has on PMs. Management's antagonism and abusive behavior toward PMs can result in identity attack, disempowerment and disengagement. While such practices were defended by the Chief Financial Officer, arguing that any cruelty was necessary in order to achieve organizational performance, it is the papers argument that psychological abuse of contemporary workers is abhorrent. The results can be seen as a costly outcome for ITOC namely, withdrawal and extensive recalcitrance, however, this is not uncommon in white-collar settings (Paulsen, 2011).

Where the expectations on the PM identity are too great it prompts the individual to ask 'what is going on here?', 'how does this affect me?', and over time 'who am I?' In ITOC, the promotion is not a common occurrence, which might be an important insight as to why PMs over time were not going above and beyond to deliver, or worse had become disengaged, and here differing from previous research. Adding to Lindgren and Packendorff's (2007) research the authors posit that these factors may lead to burn out and a temporarily damaged self-identity. Damaged self-identities will result in significant identity work from the PM, and in a sense requires reconstructions of their identity, as in the case of Haytham who after 10 years in project management felt forced to leave the project management profession altogether. Not all PMs will have either the efficacious coping strategies to deal with the role and may suffer in relative silence.

There were three cases in the case study where the lack of survival strategies was resulting in deepening identity damage, and further disengagement. While 20 PMs is a small sample, these four cases represent one fifth of PM employees in this case study site. It is acknowledged that ITOC might be a particular dysfunctional organization, in a non-western societies where 
perhaps project management is less legitimized, however, similarities with other scholars in this area is a cause for some anxiety and critical reflection. It is widely acknowledged that new professions continue to struggle with establishing legitimacy (see Fournier, 1999). PMs in this study found themselves in precarious positions as much of the risk is transferred from the client, organization, and project teams to the PM. This is perhaps due to a growing yet still lacking legitimacy of project management discipline in the GCC.

\section{Conclusions and implications}

The research set out to briefly review identity theory and to utilize one approach (of many) from identity theory to illuminate PM practice and to understand the challenges of identity regulation, identity work, and self identity from within a Middle Eastern country. The study examined the way in which PMAs and organizations together attempt to regulate the conduct of PMs and how PMs reacted to these regulatory effects. The PM as expected by PMAs and organizations proved to be considerably difficult to realize in this non-western setting, and had effects on PMs' sense of self. Reinforcing the literature reviewed, PMs were often found to be dominated by the project, by the client, or by the organization, and appeared to suffer in silence while working in difficult conditions. Lindgren et al. (2014) has recently theorized that the discourse that surrounds project managers is just part of the job, and to be endured. However this paper noted numerous strategies to protect identities to varying success were noted including careful management of the self, and deploying the science of project management back as defense mechanisms (e.g., Risk register) or 'window dressing' their projects in PMO audits.

PMs coped with and responded to attempts at identity regulation (and project life more generally) through their identity work. Wieland's work on ideal PM identities was extended to show how the PM identities are not singular but multiple and contested, and that the PMs through identity work negotiate these differences. This is consistent with Knights and Willmott (1989) claim that workers more generally construct their identity (subjectivity) in between determinism and voluntarism, that organizations do not have totalising control docile bodies. In other words, PMAs and organizations try to 'tell' PMs who they are, but PMs negotiate who they are in a particular context.

Consistent with the arguments of numerous scholars (Lindgren and Packendorff, 2007; Paton et al., 2010; Knights and Clarke, 2014) this study showed that project life can lead to intense identity work. So much so, that when circumstances go awry the PM may go through a period of temporarily damaged self-identity. Damaged here in the sense of inflicting harm on someone so as to impair his/her perception of their value or usefulness in the role of the PM function. In the case of Haythem, he found he had to leave the profession in order to save his marriage, to find time and space in the calmer operations role, to heal and reconstruct his identity. He sacrificed much for this failed project, and in the end his reputation, his confidence, and his identity were all damaged. Of course the claim is not that he is forever scarred, hence the addition of temporary, however future research might look at the longer term consequences on identity from 'failing' project management careers or projects.

While PMAs and organizations alike believe they are helping the PM with the production of rational, technical, and linear approaches. The authors believe that the results from this study call for alternative approaches that avoid what Asquin et al. (2010) calls collateral damage caused by project life. The authors suggest more support for PMs in the Gulf region: From PMAs particularly in terms of knowledge and training. From organizations, in terms of the need to understand the unique circumstances that the PM operates under, the wider muscular discourses from PMAs, and to put in place better support for PMs more generally. From researchers, in terms of taking up the invitation to contribute further in the development of human-side of research.

The sharing of this research with PMs it is hoped to encourage practitioners in project organizations to reflect on the wider consequences of project life and to bring these reflections into future research. The authors call for more research where the PM is the focus of attention and where the effects of project life on employees can be explained more comprehensively. One might comment that "this is 'just' what happens in the Gulf", however there is consistency from the works cited above in non-GCC locations. Nevertheless, in order to not over-extend identity theory's explanatory power, we stress that not all of this can be attributed to identity (as in this study) or to "accepting responsibility" (as in Lindgren et al., 2014:1405). This concern of the human effects of project management is what this paper intends to expose, that is to say this and other power mechanisms are in place. As one example in the GCC context, this other mechanism is called the kafala or sponsorship system that contributes heavily to forms of self-censorship i.e., one does not make too much fuss just in case one loses their job and get deported. Nevertheless, the insights gained from using identity theory in this organization has still be fruitful.

Future research could focus on cross organizational case studies that include a wider set of PMAs, organizations, and locations to see patterns that are more generalizable to PM populations. While the authors do not go as far as Brown (2014) to suggest that 'almost everything' can be explained by identity theory, there is still much to understand about the dynamics of identity processes and identity effects, in particular the length of time a PM might remain temporarily damaged, and what assists in the PM recovery. Other post-structural lenses can be adopted such as the work of Judith Butler, or Jacques Lacan (see Hoedemaekers and Keegan, 2010) in order to bring alternative conceptions of project manager identity.

\section{Conflict of interest}

The authors have no conflicts of interest to report.

\section{References}

Alvesson, M., Willmott, H., 2002. Identity regulation as organizational control: producing the appropriate individual. J. Manag. Stud. 39 (5), 619-644 
Alvesson, M., Lee Ashcraft, K., Thomas, R., 2008. Identity matters: reflections on the construction of identity scholarship in organisation studies. Organisation 15 (1), 5-28

Andersson, T., 2009. Who is colonizing whom? Intertwined identities in product development projects. Ephemera 9 (2), 168-181.

Asquin, A., Garel, G., Picq, T., 2010. When project-based management causes distress at work. Int. J. Proj. Manag. 28 (2), 166-172.

Beech, N., 2008. On the nature of dialogic identity work. Organisation 15 (1), $51-74$.

Brown, A., 2014. Identities and Identity Work in Organizations. International Journal of Management Reviews.

Buchanan, D.A., 1991. Vulnerability and agenda: Context and process in project management. Br. J. Manag. 2 (3), 121-132.

Butler, J., 2005. Giving an Account of Oneself. University Press, Fordham.

Chia, R., 1995. From modern to postmodern organization analysis. Organ. Stud. 16 (4), 579-604

Collinson, D.L., 2003. Identities and insecurities: selves at work. Organisation $10(3), 527-547$

du Gay, P., 1996. Consumption and Identity at Work. SAGE.

Easterby-Smith, M., Thorpe, R., 1991. Management Research: An Introduction. SAGE, London.

Fournier, V., 1999. The appeal to "professionalism" as a disciplinary mechanism. Sociol. Rev. 47 (2), 280-307.

Geertz, C., 1973. The Interpretation Of Cultures. Basic Books, New Yorks.

Giddens, A., 1991. Modernity and Self-Identity. Self and Society in the Late Modern Age. Polity, Cambridge.

Gillham, B., 2005. Research Interviewing. McGraw Hill Education.

Gunz, H., Gunz, S., 2007. Hired professional to hired gun: an identity theory approach to understanding the ethical behaviour of professionals in nonprofessional organizations. Hum. Relat. 60 (6), 851-887

Hobday, M., 2000. The project-based organisation: an ideal form for managing complex products and systems? Res. Policy 29, 871-893.

Hodgson, D., 2002. Disciplining the professional: the case of project management*. J. Manag. Stud. 39 (6), 803-821.

Hodgson, D., Cicmil, S., 2006. Making Projects Critical. Palgrave MacMillan.

Hodgson, D.E., Paton, S., 2015. Understanding the professional project manager: cosmopolitans, locals and identity work. Int. J. Proj. Manag. http://dx.doi.org/ 10.1016/j.ijproman.2015.03.003 (forthcoming).

Hoedemaekers, C., Keegan, A., 2010. Performance pinned down: studying subjectivity and the language of performance. Organ. Stud. 31 (8), 1021-1044

Jian, 2011. Articulating circumstance, identity and practice: toward a discursive framework of organisational changing. Organisation 18 (1), 45-64.

Knights, D., Clarke, C.A., 2014. It's bittersweet symphony, this life: fragile academic selves and insecure identities at work. Organ. Stud. 35 (3), 335-357.
Knights, D., Willmott, H., 1989. Power and subjectivity at work: from degradation to subjugation in social relations. Sociology 23 (4), 535-558.

Legault, M., Chasserio, S., 2011. Professionalisation, risk transfer and effect on gender gap in project management. Int. J. Proj. Manag. 30 (6).

Lindgren, M., Packendorff, J., 2007. Performing arts and the art of performing — on co-construction of project work and professional identities in theatres. Int. J. Proj. Manag. 25 (4), 354-364

Lindgren, M., Packendorff, J., Sergi, V., 2014. Thrilled by the discourse, suffering through the experience: emotions in project-based work. Hum. Relat. 67 (11), 1383-1412.

Mintzberg, H., 1983. Structure in Fives: Designing Effective Organisations. Prentice Hall.

Nach, H., Lejeune, A., 2010. Coping with information technology challenges to identity: a theoretical framework. Comput. Hum. Behav. 26 (4), 618-629.

Paton, S., Hodgson, D., Cicmil, S., 2010. Who am I and what am I doing here?: becoming and being a PM. J. Manag. Dev. 29 (2), 157-166.

Patton, M., 2002. Qualitative Research and Evaluation Methods. Sage Publications, Thousand Oaks, CA.

Paulsen, R., 2011. Outlines-Critical Practice Studies [WWW]. http://www. outlines.dk.

Richmond, A., Skitmore, M., 2006. Stress and coping: A study of PMs in a large ICT organisation. Proj. Manag. J. 37 (5), 5-16.

Schwalbe, M., 1996. Identity work as group process. Adv. Group Process. 13, 113-147.

Stuart, Albert, Whetten, David A., 1985. Organizational identity. In: Cummings, Larry L., Staw, Barry M. (Eds.), Research in organizational behavior. An annual series of analytical essays and critical reviews. JAI Press, Greenwich, pp. 263-295.

Sveningsson, S., Alvesson, M., 2003. Managing managerial identities: organisational fragmentation, discourse and identity struggle. Evaluation 56 (10), 1163-1193.

Tajfel, H., Turner, J., 1979. An integrative theory of intergroup conflict. The social psychology of intergroup relations? 33, 47.

Thornborrow, T., Brown, A.D., 2009. 'Being regimented': aspiration, discipline and identity work in the British Parachute Regiment. Organ. Stud. 30 (4), 355-376.

Van Donk, D., Molloy, E., 2008. From organising as projects to projects as organisations. Int. J. Proj. Manag. 26 (2), 129-137.

Wieland, S.M.B., 2010. Ideal selves as resources for the situated practice of identity. Manag. Commun. Q. 24 (4), 503-528.

Zika-Viktorsson, A., Sundström, P., Engwall, M., 2006. Project overload: an explanatory study of work and management in multi-project settings. Int. J. Proj. Manag. 24, 385-394 